\title{
ENSINO MÉDIO INTERMEDIADO POR TECNOLOGIA: A UTILIZAÇÃO DAS TECNOLOGIAS DIGITAIS DE INFORMAÇÃO E COMUNICAÇÃO NA REDUÇÃO DE CUSTOS E NO COMBATE DO ABANDONO E EVASÃO ESCOLAR
}

\begin{abstract}
Alécio de Andrade Souza ${ }^{\mathrm{X}}$
RESUMO: Há relevantes aspectos das Tecnologias da Informação e da Comunicação TICs que geram impactos na vida contemporânea causando impactos, inclusive, no âmbito da educação, trazendo relevantes possibilidades para diminuir a evasão e o abandono durante o ensino médio. Contudo, as TICs não podem ser consideradas como um simples meio ou apenas como suporte na transmissão de conteúdo e informação, mas, sobretudo, deve ser reconhecida como uma ferramenta permanente e adequada para despertar o interesse dos estudantes e oportunizar a concretude da educação básica. Nesse sentido é importante ressaltar que a integração entre as TICs e os diversos campos da educação e do ensino podem colaborar para experiências exitosas na aprendizagem. Nesse sentido destaca-se ainda que as TICs podem diminuir os custos e os gastos com as despesas na educação, pois o conteúdo digital torna mais acessível e barata a manutenção dos educadores e passam inclusive a alcançar alunos que residem em locais onde não oferta regular de ensino. Neste trabalho foram evidenciados, como resultados, as implicações positivas e propositivas das TICs como elemento da mediação e modernização na aprendizagem e para o desenvolvimento de práticas pedagógicas ligadas às necessidades de nosso tempo.
\end{abstract}

Palavras-chave: Educação. Aprendizagem. AVA. Educação tecnológica.

\section{INTRODUÇÃO}

As transformações sociais e estruturais oriundas das diversas revoluções tecnológicas, em especial as ocorridas nos últimos anos, transformaram de maneira significativa o comportamento e a organização da sociedade.

O que precisa ser pontuado e esclarecido é que a sociedade não é mais imaginada dissociada da forte influência da tecnologia, seja pela modernização dos processos organizacionais, seja por meio da velocidade da informação que alimenta a urgência das

\footnotetext{
I Doutor em Ciências da Educação: Universidad Interamericana - PY (2020). Mestre em Ciências da Educação: Universidad Interamericana - PY (2018). Psicanalista - Associação Brasileira de Psicanálise-DF (2013). Especialista em Educação Ambiental: UNIBAHIA - (2008). Especialista em Gestão Ambiental: FTC -(2007). Especialista em Planejamento e Interpretação de Atividades em Áreas Naturais: UFLA - (2006). Licenciado em Geografia pela Universidade Estadual do Sudoeste da Bahia (2004), aleciosouza@hotmail.com.
} 
demandas e das expectativas, sociais e econômicas, o que impacta de modo a causar grandes impactos ante o consumo de tecnologias da informação e comunicação.

As TICs trouxeram para a sociedade uma série de novos paradigmas e mudanças comportamentais, em especial na seara da educação, possibilitando repensar as práticas pedagógicas que passaram a ser reorganizadas para se adaptarem e serem atualizadas, garantindo dessa forma que as escolas e os gestores da educação tenham condições de expandir o ensino e tecer maiores ganhos no que diz respeito a aprendizagem.

Para a construção deste trabalho, foram consideradas as informações dos dados obtidos por meio do Inep e do EMITec, demonstrando as relevantes contribuições da intervenção digital nos processos de aprendizagem e nas questões acerca da mediação tecnológica compreendendo o uso das TICs e tendo como resultado a diminuição do abandono escolar e melhores aproveitamentos no que diz respeito à aprovação.

\section{REFERENCIAL TEÓRICO}

\subsection{Reprovação e abandono escolar no ensino médio: fatores, causas, indicadores e possíveis consequências.}

Destaca-se no cenário atual, elevado número de jovens que desistem do ensino médio no Brasil, nesse sentido, deve-se observar as possíveis causas e fatores que podem influenciar nesse sentido.

Dessa feita, de ordem a indicar os fenômenos que podem interferir na reprovação e consequentemente causar o abandono escolar.

De acordo com Brandão:

\footnotetext{
Ninguém escapa da educação. Em casa, na rua, na igreja ou na escola, de um modo ou de muitos todos nós envolvemos pedaços da vida com ela: para aprender, para ensinar, para aprender-e-ensinar. Para saber, para fazer, para ser ou para conviver, todos os dias misturamos a vida com a educação. (BRANDÃO, 1985, p.7)
}

A evasão de alunos é um dos problemas que está muito presente em todas as instituições educacionais e em todos os níveis de ensino. Não se pode limitar a discutir essa problemática apenas observando fatores externos ao contexto do ensino, pois para além dos fatores sociais e econômicos, deve-se levar em conta que a escola necessita 
tornar-se mais moderna e conectada com as tecnologias e as novas plataformas de disponibilização de dados e informações.

O problema da evasão não está adstrito apenas às instituições públicas, pois são vários os motivos pelos quais levam as instituições privadas também passam a ter uma maior preocupação com o problema da evasão. No entanto, para o setor público há maiores prejuízos haja visto que os recursos investidos requerem retorno e planejamento para sua aplicação.

Evasão escolar no âmbito do Brasil é um fenômeno complicado a ser compreendido e enfrentado, haja vista as dimensões continentais do território brasileiro, bem como as distorções regionais no que diz respeito à qualidade de vida e o índice de desenvolvimento humano, aspectos que devem ser levados em conta para que a compreensão do problema possa ter projetos e atuação estatal na necessária intensidade para suprir as carências humanas, logísticas, metodológicas e institucionais.

Podemos compreender que os problemas pelo quais a evasão ocorre passam pela a falta de interesse, uma das principais causas, a qual resulta, além do conteúdo ser exagerado, ser descontextualizado, esse raciocínio é compartilhado além dos alunos, pois os professores também enxergam que mudanças profundas precisam ocorrer para que esse problema seja enfrentado.

De acordo com os dados do Instituto Nacional de Educação e Pesquisas Educacionais Anísio Teixeira:

Gráfico r: Índice de abandono no ensino médio brasileiro

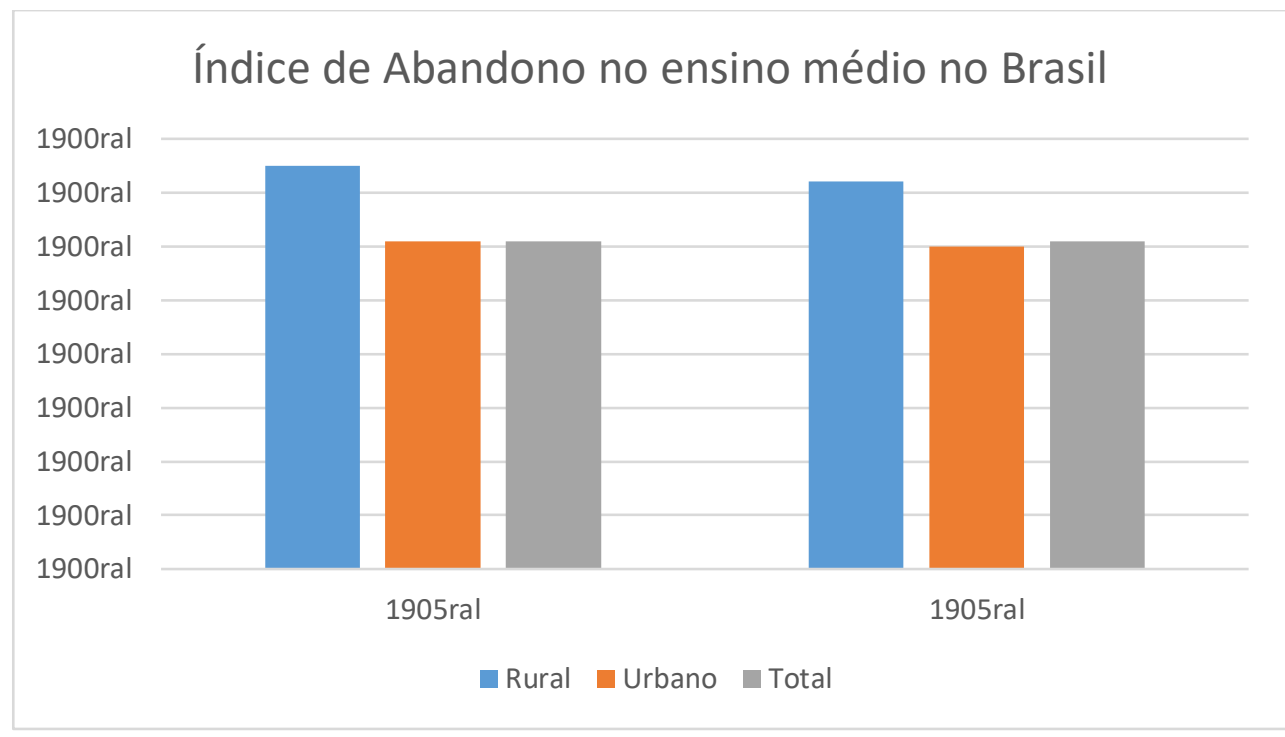

Fonte: Inep, 2019 
No gráfico apresentado verifica-se que a relação de abandono do ensino médio nos anos de 2017 e 2017 foram mais expressivas com relação aos alunos de escolas em regiões rurais, pois enquanto o abandono nas escolas urbanas praticamente manteve o mesmo patamar, o mesmo não ocorreu com a educação rural.

Nesse sentido, figura a necessidade de implementar modelos mais sólidos para evitar a evasão dos estudantes de escolas rurais, a começar pela necessidade de estimular os alunos e desenvolver ferramentas que diminuam o peso no orçamento, bem como facilitem a interação entre alunos e professores.

Podemos destacar o exemplo desenvolvido pelo programa Ensino Médio intermediado pela Tecnologia - EMITec, que no âmbito do Estado da Bahia desenvolve uma prática integrativa que é comporta por uma rede de serviços de comunicação multimídia, onde há integração de dados, voz e imagem, desse modo se constitui em uma ferramenta pedagógica que objetiva atender a jovens e adultos, residentes de localidades que contem com difícil acesso em relação a centros de ensino e aprendizagem e também em locais onde não exista oferta do ensino médio.

Verifica-se no gráfico abaixo que o EMITec apresenta melhores resultados quando comparado aos números alcançados pelo estado da Bahia e pelo consolidado nacional. O índice de aprovação do EMITec foi $18,3 \%$ maior que a aprovação total no estado da Bahia e 8,8\% maior que a aprovação no Brasil, com relação à evasão e a reprovação também foram inferiores aos que ocorreram na Bahia e no Brasil.

Parte desse resultado se deve ao formato e a gestão de dados e recursos que são organizados metodologicamente por meio dos processos digitais envolvidos no EMITec. Nesse sentido, a aprovação e a reprovação estão demonstradas nos dados, diretamente relacionadas com a oferta de educação igualitária e de qualidade, como se pode observar, o EMITec é responsável por dinamizar o ensino e desenvolver ferramentas que oportunizam que os estudantes que residem em locais longínquos tenham a oportunidade de acesso à educação básica de qualidade.

Acerca da distorção entre a idade e a série (idade regular), há de se destacar que na Educação para Jovens e Adultos - EJA, há grandes possibilidades para os meios digitais, por dinamizar o conteúdo e possibilitar que as aulas possam ocorrer no modelo de Educação a Distância - EaD. 


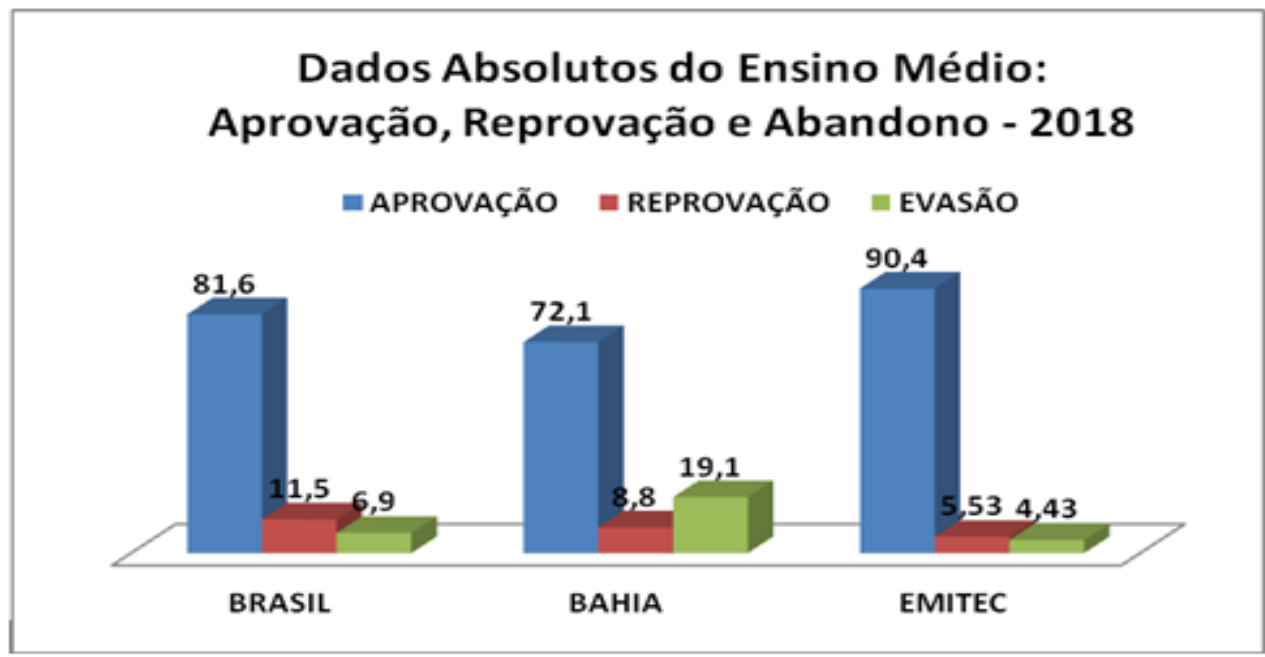

Fonte: EMITEC, 2019.

Nesse sentido, conforme as informações verificadas junto ao EMITec, a evasão escolar compreendida entre o período de 2011 a 2018 demonstra que houveram aumentos na quantidade de matrículas e aprovação, contudo, o aumento também ocorreu nas reprovações e no abandono escolar, o que implica dizer, apesar do aumento exponencial de I2.877 no ano de 2011 para 18.418 no ano de 2018 , ainda restam problemas a serem sanados para que se possa minimizar a evasão. As informações aqui aferidas encontram-se no gráfico abaixo:

Gráfico 3: Aprovados e reprovados no EMITec 2011-2018

\section{APROVADOS x REPROVADO NO EMITEC: 2011 - 2018}

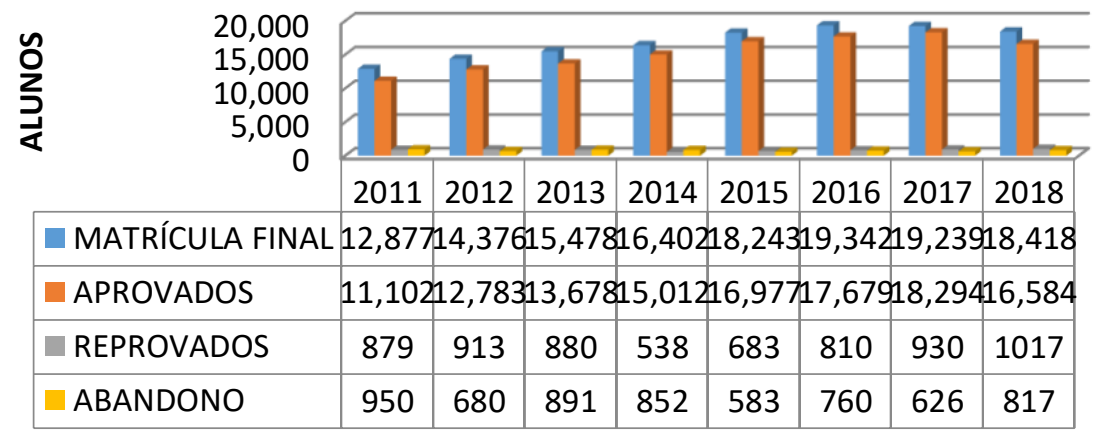

Fonte: EMITEC, 2019. 
Verifica-se que o EMITec possui um percentual de dentro dos parâmetros nacionais no que diz respeito ao abandono pelos estudantes do ensino médio, implica dizer ainda que, mesmo a quantidade estando dentro do quadro nacional, houveram avanços e melhorias no quadro do EMITec, considerando que entre 2011 e 2018 houve queda na quantidade de abandono.

Com base nas informações anteriormente apresentadas podemos inferir que a evasão escolar é uma problemática que passa por diversos fatores e concorre com o uso regular dos recursos públicos objetivando os melhores resultados e eficiência.

Nesse sentido:

\footnotetext{
Resulta de múltiplos fatores e permite ampliar um repertório de informações e desenvolvimento de habilidades compostas por uma pluralidade de conhecimentos teórico-práticos, capazes de consolidar a formação de jovens, ressignificando-lhes a aprendizagem, preparando-os para o mundo do trabalho, pautando-se para tal em princípios de interdisciplinaridade, contextualização, transdisciplinaridade, democratização, privilegiando a pertinência e a relevância social, ética, estética, tornando esse jovem partícipe de sua história, capaz de alterar e intervir positivamente na sociedade e, principalmente, na comunidade em que estiver inserido (MINAS GERAIS, 2013, p.22).
}

Apresenta-se como um programa capaz de conduzir às mudanças necessárias para o enfrentamento à evasão. No entanto, as modificações versadas na presente resolução não levam em contas as características de investimento, como melhorias na infraestrutura, equipamentos nas unidades escolares e recursos que sejam destinados, dentre outras coisas, à modernização e criação de ambientes virtuais de aprendizagem.

\subsection{As tecnologias como instrumentos que influenciam a redução do abandono e evasão escolar de alunos no ensino médio hibrido}

Atualmente, um dos desafios no contexto da educação contemporânea é atender aos anseios dos estudantes que chegam às escolas, pois as relações humanas foram significativamente afetadas pelo modo como lidamos com as tecnologias e as instituições de ensino, em sua maioria, ainda insistem em trabalhar com o modo transmissivo de conhecimento, totalmente tradicional e centrado na figura do professor.

No Artigo 205, da Constituição Federal do Brasil consta que: 
A educação, direito de todos e dever do Estado e da família, será promovida e incentivada com a colaboração da sociedade, visando ao pleno desenvolvimento da pessoa, seu preparo para o exercício da cidadania e sua qualificação para o trabalho (BRASIL, I988).

A capacitação dos profissionais da educação é uma ferramenta que auxilia no combate à evasão escolar, haja visto que a implantação de projetos e mudanças profundas requer um preparo mínimo por parte dos educadores e das instituições de ensino e capacitação profissional. No entanto, atual cenário de cortes de gastos e remanejamento de despesas, o que vigora é o arrocho orçamentário o que prejudica e dificulta a implantação de projetos que tenham a finalidade de modernizar e atualizar os imperativos para uma educação suporte efetivo das tecnologias.

O Ensino médio híbrido, conforme Moran e Bacich:

Híbrido significa misturado, mesclado, blended. A educação sempre foi misturada, híbrida, sempre combinou vários espaços, tempos, atividades, metodologias, públicos. Esse processo, agora, com a mobilidade e a conectividade, é muito mais perceptível, amplo e profundo: é um ecossistema mais aberto e criativo. Podemos ensinar e aprender de inúmeras formas, em todos os momentos, em múltiplos espaços. Híbrido é um conceito rico, apropriado e complicado. Tudo pode ser misturado, combinado, e podemos, com os mesmos ingredientes, preparar diversos "pratos", com sabores muito diferentes. (2015, p.22).

O aspecto colaborativo é parte fundamental com a utilização das tecnologias digitais, pois a educação híbrida é sinônimo de troca, de interatividade, nesse sentido caminha para possibilitar a construção do conhecimento com a participação ativa do estudante e a colaboração dos professores e gestores do ensino.

Assim, as tecnologias possuem o potencial de dirimir o abandono e a evasão escolar no ensino médio. Considerando inclusive o que as metodologias precisam acompanhar os objetivos pretendidos.

As metodologias precisam sem conectadas com os objetivos para que as finalidades sejam condizentes com os resultados almejados.

A convivência nos espaços híbridos multimodais da hiperconexão provoca mudanças nos modos de interagir, representar o pensamento, expressar emoções, produzir e compartilhar informações e conhecimentos, assim como aporta novos elementos à aprendizagem, podendo trazer novas contribuições e desafios aos processos educativos (VALENTE, ALMEIDA E GERALDINI, 2017). 
A necessidade de encontrar outras possibilidades que possam colocar em prática um novo perfil de educação no qual o aluno e professor colaborem juntos numa metodologia híbrida e assistida pelo potencial dos aparatos e instrumentos tecnológicos é uma realidade irremediável.

Quando se discute uma educação contemporânea, vários estudos, metodologias e modelos que foram escritos, criados e implantados combinando recursos tecnológicos com práticas presenciais e online, na busca de autonomia e proatividade do estudante na busca da aprendizagem significativa.

Assim, cabe compreender que o direito à educação deve ser interpretado como o direito ao pleno desenvolvimento, seu sentido amplo compete nesse sentido à busca pela qualidade e pela aquisição de meios para que o estudante possa exercer a aprendizagem efetiva. Cabe salientar que a evasão pode ser reduzida no caso aos quais os estudantes desistem da escola pelo desinteresse e pela falta de motivação. Há ainda de se destacar que o direito à educação não pode ficar restrito ao acesso à escola.

Nesse sentido:

\footnotetext{
Neste contexto sem ignorar as questões extraescolares não se pode deixar de enfrentar que o fracasso escolar, bem como a evasão, constitui um problema pedagógico. É no estudo do cotidiano da escola que vários autores têm apontado possibilidades concretas de transformação de suas práticas, como forma de enfrentamento problema. (PATTO, 1987, p.238)
}

A escola tem a possibilidade de tornar-se uma instituição com a finalidade de ser igualitária, oportunizando uma educação a todos e ser ela a responsável pela reprodução e transformação das condições de aprendizagem, inclusive possibilitando o protagonismo individual para combater distorções e efetivar os princípios no qual assentam as perspectivas nacionais da constituição.

Nesse contexto, para a aprendizagem escolar híbrida seja uma experiência estimulante e socialmente ativa, há de se considerar como indispensável a mediação que o professor possa atuar como mediador e colaborador entre o conhecimento a médio e longo prazo, especialmente com o domínio dos meios e metodologias aplicados aos conhecimentos que devem ensinados.

De acordo com: 
Educação não é a modelagem de pessoas, porque não temos o direito de modelar a partir do seu exterior, também não é a mera transmissão de conhecimentos, mas a produção de uma consciência verdadeira, isto seria inclusive da maior importância política, formando pessoas emancipadas, conscientes e racionais. (ADORNO, 1995, p.I4I-I42)

Assim as tecnologias podem contribuir para diminuir a evasão escolar e tornar-se um elemento indispensável no contexto da educação híbrida.

\subsection{As tecnologias como estratégia para redução de custos no ensino médio hibrido.}

As tecnologias digitais alçam um espaço cada vez maior na vida doméstica, no mercado de trabalho, na educação e nos meios de comunicação e relações sociais.

Para que a educação possa haurir benefícios com as mudanças da revolução digital, dinamizando seus meios e a estrutura organizacional das metodologias de ensino é imperioso que se verifique como algumas estratégias podem ser importantes para que os custos com a educação sejam barateados, nesse sentido, a competitividade e inclusão, absorvendo a digitalização em seus processos, valores e conhecimento pode trazer melhores condições para a subsistência da educação, a saber, pelas diversas possibilidades de leitura por meio de bibliotecas virtuais, vídeos, conteúdo interativo e as construções compartilhadas.

Assim, o planejamento orçamentário deve considerar novas práticas mais sustentáveis e engajadoras, que otimizem o uso de recursos e possam efetivar a aprendizagem significativa, especialmente quando planejada com a contribuição para reduzir os custos na escola.

Nesse sentido, ao colaborar diretamente na efetivação dos direitos da cidadania e orçamento eficiente, a educação relaciona-se diretamente com o desenvolvimento de uma consciência responsável e antenada, evidenciando protagonismo e amadurecimento de gestão de recursos e competências, especialmente quando se objetiva resultados inovadores e mudanças nas condições sociais.

De acordo com Freire e Shor (1992):

Aravés da educação, podemos de saída compreender o que é o poder na sociedade, iluminando as relações de poder que a classe dominante torna obscuras. Também podemos nos preparar e participar de programas para mudar a sociedade (FREIRE; SHOR, 1992, p. 44) 
Pode-se compreender a educação híbrida como um fenômeno dividido em momentos, em alguns o aluno estuda sozinho, nesse momento é possível se valer do potencial das tecnologias para que o estudante tenha controle sobre seus estudos, tomando decisões que favoreçam sua autonomia.

Deve-se salientar também que a reprovação causa graves prejuízos aos cofres públicos, haja visto que o mesmo estudante receberá os mesmos recursos e passará mais tempo para sua formação, obrigado a gestão pública, nesse caso, a limitar os investimentos aos estudantes ingressantes, nesse sentido há um impacto negativo e demasiadamente prejudicial ante a reprovação escolar, pois além dos malefícios pedagógicos, há transtornos orçamentários.

O abandono de alunos custa caro aos cofres públicos, estima-se que, o custo social em média com cada jovem que não conclui o ensino médio é de 95 mil reais, acordo com dados do Insper (2019).

Ainda de acordo com o Insper:

As consequências de não concluir o ensino médio transbordam a esfera privada porque trabalhadores mais qualificados são mais produtivos, atraem mais investimentos e demandam menos gastos públicos com saúde, combate ao crime e bem-estar social. [...] A perda estimada com emprego e renda do jovem sem ensino médio, ao longo da vida, equivale a $\mathrm{R} \$ 49 \mathrm{mil}$ ou $170 \%$ da renda per capita. Esse perfil de jovem estimula pouco o desenvolvimento de competências nas pessoas com quem trabalha e atrai menos investimentos.

Para cada concluinte do ensino médio, a redução estimada na criminalidade gera economia de $63 \%$ da renda per capita ao longo da vida. A sociedade poupa $R_{\$}$ I8 mil em combate ao crime.

Adultos que não concluem o ensino médio em geral têm piores condições de saúde, o que eleva as despesas médicas e hospitalares, além das faltas no trabalho. O custo para a sociedade da evasão associado à pior condição de saúde é de $97 \%$ da renda per capita, ou R $\$ 28$ mil. (2019)

Dessa feita, verifica-se que os custos com a evasão escolar causam grandes transtornos pois além de não concluírem a formação escolar básica dos jovens também afetam a prestação pública de outros serviços a toda a sociedade.

Ainda com relação a economia causada pelo EMITEC, destaca-se o fato de os alunos não precisarem se deslocar de suas residências para as escolas, visto que os processos tecnológicos alcançam inclusive os lugares mais longínquos. 
Nesse sentido deve ser pontuada também a redução orçamentária com a contratação de menos profissionais, pois havendo o conteúdo é construído e direcionado com um núcleo estruturante responsável pela organização e gestão de pedagógica.

\section{CONSIDERAÇÕES FINAIS}

Quando se discute a temática da educação e das TICs, surgem a cada momento diversas convergências e divergências nas diversas discussões que se dão no meio acadêmico, entretanto, as tecnologias da informação e comunicação bem como os impactos que essas causam na educação formal, não podem mais ser negligenciados ou deixados de lado.

Os desafios não são apenas de ordem técnica ou operacional, mas de planejamento e gestão que precisam considerar os novos arranjos possíveis para o âmbito educacional, que deve ter uma visão que contemple as inovações tecnológicas, a exemplo do EMITec.

Nesse sentido é relevante considerar que ainda existe, por parte dos profissionais da educação, poucas iniciativas, mas crescente expansão, acerca da necessidade de se pensar práticas pedagógicas que incluem as diretrizes das TICs. Dessa feita a educação assistida pelo suporte das TICs se consolida como o campo aberto a diversas experiências e que promove, efetivamente, a inclusão da escola plural.

\section{REFERÊNCIAS}

ADORNO, Theodor W. Educação e emancipação. Rio de Janeiro: Paz e Terra, 2003.

BRANDÃO, Carlos Rodrigues. O que é educação. São Paulo: Brasiliense, 1985.

BRASIL. Constituição da República Federativa do Brasil de 1988. Brasília: planalto, 2019. Disponível em:http://www.planalto.gov.br/ccivil_03/Constituicao/ Constituicao.htm. Acesso em: II nov. 2020..

FREIRE, P. \& SHOR, I. Medo e Ousadia: O cotidiano do Professor. Rio de Janeiro: Paz e Terra, 1992.

INEP. Indicadores Educacionais. Disponível em: http://portal.inep.gov.b r/web /guest/indicadores-educacionais. Acesso em: Io nov. 2020. 
INSPER. Evasão escolar custa $\mathbf{R} \$ 124$ bilhões. Disponível em: https://www.insper.edu.br/conhecimento/politicas-publicas/custo-evasao-escolar/. Acesso em: io nov. 2020.

MINAS GERAIS. Resolução SEE no 2486, de 20 de dezembro de 2013. Dispõe sobre a universalização do Reinventando o Ensino Médio nas Escolas da rede pública estadual de Minas Gerais. Minas Gerais, 2013.

MORAN, José Manuel. BACICH, Lilian. Aprender e ensinar com foco na educação híbrida. Disponível em: http://www2.eca.usp.br/moran/wpcontent/ uploads/2015/o7/hibrida.pdf. Acesso em: 05 nov. 2020.

PATTO, Maria Helena Souza. A produção do fracasso escolar: histórias de submissão e rebeldia, 1987.

VAlENTE, J. A.; AlMEIDA, M. E. B. de; GERAlDini, A. F. S. Metodologias ativas: das concepções às práticas em distintos níveis de ensino, 2017. Rev. Diálogo Educ., Curitiba, v. 17, n. 52, p. 455-478, abr./jun. 2017. 